\title{
Development and validation of a training module on the use of acetic acid for the detection of Barrett's neoplasia
}

Chedgy FJQ, Kandiah K, Barr H, De Caestecker J, Dwerryhouse S, Eross B, Gordon C, Green S, Li A, Brown J, Longcroft-Wheaton G, Bhandari P.

\section{Abstract}

\section{Background and Aims}

Acetic acid chromoendoscopy (AAC) enhances the ability to correctly identify Barrett's neoplasia and is increasingly used by both expert and non-expert endoscopists. Despite its increasing use, there is no validated training strategy to achieve competence. The aims of our study were to; develop a validated training tool in AAC-assisted lesion recognition, assess endoscopists baseline knowledge of AAC-assisted lesion recognition and evaluate the efficacy and impact of this training tool.

\section{Methods}

A validated assessment of 40 images and 20 videos was developed. 13 endoscopists with experience of Barrett's endoscopy but no formal training in AAC were recruited into the study. Participants underwent: baseline assessment (1) $\rightarrow$ online training $\rightarrow$ assessment $\quad$ (2) $\rightarrow$ interactive seminar $\rightarrow$ assessment (3).

\section{$\underline{\text { Results }}$}

Baseline assessment demonstrated a sensitivity of $83 \%$ and negative predictive value (NPV) $83 \%$. Our online training intervention significantly improved sensitivity to $95 \%$ and NPV to $94 \%(p<0.01)$. Further improvement was seen with a one-day interactive seminar with live cases, increasing sensitivity to $98 \%$ and NPV to $97 \%$. 


\section{Conclusions}

Our data demonstrate the need for training in AAC-assisted lesion recognition as baseline performance, even by Barrett's experts, was poor. We were successful in developing and validating an online training and testing tool for AAC for Barrett's neoplasia. Training intervention with our tool improves performance of endoscopists to meet ASGE PIVI standards. The training tool increases the endoscopist's degree of confidence in the use of AAC. The training tool also leads to shift in attitudes of endoscopists from Seattle protocol towards AAC guided biopsy protocol for Barrett's surveillance. 
Barrett's esophagus (BE) carries a risk of cancer 30-150 times greater than that for an age-matched population without BE [1]. Five-year-survival rates following the diagnosis of esophageal cancer are less than 15 percent [2]. The annual rate of transformation into esophageal adenocarcinoma (EAC) in patient's with non-dysplastic BE is estimated to be between $0.07 \%$ to $0.82 \%[3,4]$. However, the annual rate of progression from low-grade dysplasia (LGD) to high-grade dysplasia (HGD) or EAC is as high as 6.5\%[5-7] and from HGD to EAC is 12-40\% [8-10]. Detecting and treating dysplasia is the only way to prevent cancer developing. Current British Society of Gastroenterology (BSG) guidelines [11] recommend 2-to-5 yearly surveillance endoscopy with quadrantic, $2 \mathrm{~cm}$ biopsies. This approach is recommended as dysplasia in Barrett's is often flat, patchy and difficult to detect, with only $13 \%$ of lesions appearing as visible nodules[12]. These Seattle protocol biopsies may miss up to $40 \%$ of treatable cancers [13]. It is well-recognised that the protocol is poorly adhered to with studies reporting only $51 \%$ of patients receiving the appropriate number of biopsies; the longer the length of Barrett's the worse the adherence [14,15].

To redress these limitations, a number of approaches have been suggested for visualising the neoplastic areas, enabling targeted-biopsy, including; dye sprays $[16,17]$ and electronic imaging enhancement, such as tri-modal imaging [18-20]. Acetic acid (AA) is a weak fatty-acid that, when sprayed on Barrett's mucosa, highlights surface patterns and causes an acetowhitening reaction (Figure 1 and Video 1)[21]. Dysplastic areas lose the acetowhitening effect faster than nondysplastic areas[22], highlighting areas for targeted-biopsy (Figure 2 and Video 2). This process is reversible and causes no damage to tissues. Two large cohort studies have demonstrated the effectiveness of $A A$ in dysplasia detection in high-risk populations [23,24], demonstrating sensitivities for dysplasia detection of $90-95 \%$ and specificities $75-85 \%$. Further work from the same groups have suggested that the number of biopsies needed to detect neoplasia could be significantly reduced if AA-targeted biopsies were used in place of Seattle protocol biopsies, reducing pathology related costs by $97 \%$ [25]. Tholoor et al. [26] reported the use of AA in a surveillance population, demonstrating a six-fold increase in neoplasia detection as compared to Seattle protocol biopsies, with a fifteen-fold decrease in the number of biopsies required. Pohl et al.[24] demonstrated in their large cohort study that the number of AA-targeted biopsies required to yield one diagnosis of dysplasia is 5.2, as compared to 228 mapping biopsies.

The ASGE recently published key performance indicators for targeted-biopsies in Barrett's neoplasia, suggesting cut offs for sensitivity of $\geq 90 \%$, negative predictive value $\geq 98 \%$ and specificity of $80 \%$ [27]. Current published literature is suggestive that AA meets these criteria. However, the 
accuracy of acetic acid chromoendoscopy (AAC) has only been reported by experts in tertiary centres. Prior to widespread uptake of this technique clinicians will need to be trained to achieve acceptable accuracy, sensitivity and specificity.

This study reports on the development and validation of a training programme for AAC-assisted lesion recognition by means of an online training module, incorporating still-images and dynamic moving videos, as well as an interactive seminar including observed live procedures. Diagnostic performance and inter-observer agreement for each stage of training was assessed.

\section{Methods}

This was a prospective, educational evaluation study conducted at a tertiary referral centre for $\mathrm{BE}$ between March and April 2015. The study was approved by the National Health Service (NHS) Research Ethics Committee, reference number REC 15/SC/0085. The primary aim of this study was to develop and validate a training and assessment programme for AAC. The primary endpoints were to determine the construct validity of the image and video-based test (i.e. that the test appropriately differentiates between experts and non-experts) and determine the content validity of the training module for each stage of training.

\section{Module development}

A literature review was performed to identify key features of AAC in Barrett's. Based on this a novel AA classification was developed and validated[28] and learning objectives for the training programme identified. To meet these objectives an online training module was developed using the Moodle platform (Moodle Pty Ltd, Perth, Australia), hosted by the University of Portsmouth. The online platform was split into 7 chapters:

1) Background and rationale behind $A A$ use

2) Validated AA classification:

a. Focal early loss of acetowhitening (LAW): Yes/No

b. Surface pattern:

i. Large uniformly distributed pits (normal pit density) OR 
ii. Compactly packed pits, smaller than surrounding mucosa (increased pit density) OR

iii. Focal irregularity or disorganised pits

iv. Absent surface pattern

3) Lesion morphology: nodular/flat/depressed

4) Benign Barrett's examples: images and videos

5) Dysplastic Barrett's examples: images and videos

6) Intramucosal cancer examples: images and videos

7) In training quiz using both images and videos with direct feedback on answers.

High definition (HD) still-images and videos of Barrett's 2.5\% AAC with corresponding histology were sourced from an established library of over 500 procedures. Images and videos were selected and reviewed by research fellows (FC, KK) for quality and visibility of the key features of AAC. Images and videos used for training were not repeated in the assessment. Videos were edited to demonstrate the Barrett's segment in HD white light and following application of AA. Biopsies were not included in videos to avoid bias. Images were taken from video-clips and stored in portable network graphic (PNG) format, videos were edited in MP4 format and deliberately did not overtly focus on areas of abnormality.

40 still-images (21 benign, 19 neoplasia) and 20 videos (10 benign, 10 neoplasia) were chosen for the assessment tool, totalling 60 individual cases. Although the majority of patients have nondysplastic $\mathrm{BE}$, a heterogeneous mix of dysplastic and non-dysplastic cases was required to obtain unbiased accuracy rates. Only cases of HGD and intramucosal cancer (IMC) were used, as invasive cancer is generally obvious. The training module consisted of 8 images ( 4 benign and 4 neoplastic) and 9 videos ( 3 benign and 6 neoplastic). Images and videos were annotated to describe the keyfeatures of AAC-assisted lesion recognition. Included within the training module was a sample quiz of 8 questions providing immediate feedback (Figure 3), with a clear explanation of the diagnosis focusing on surface pattern, LAW reaction and morphology. Endoscopists were unable to access the training module without first completing the baseline assessment. The training module could be repeated as many times as the participant wished. Participants were not required to complete the online training module and assessments in one session. Having completed the training module, the same assessment exercise was immediately repeated without feedback on prior performance. 
13 endoscopists took part in all stages of the study, all of whom were nationally certified, independent endoscopists with experience in Barrett's endoscopy but no prior formal training in AAC-assisted lesion recognition. The group consisted of 5 consultant gastroenterologists, 2 consultant upper GI surgeons and 6 nurse endoscopists (see Table 1).

All were required to complete the training module prior to attending the live-interactive workshop held at Queen Alexandra Hospital on $24^{\text {th }}$ April 2015. A state-of-the-art lecture (PB) was given, reiterating the key features of AAC-assisted lesion recognition. 5 live-cases were performed with endoscopists observing via interactive video-link. Cases were carefully preselected to include 2 cases of non-dysplastic Barrett's, 2 cases of dysplastic Barrett's and 1 case of IMC, affording the opportunity for endoscopists to question and discuss the techniques employed and view real-time application of AA. At the end of the interactive seminar endoscopists immediately repeated the same assessment exercise without feedback on performance. Figure 4 shows a flow diagram of our training interventions.

Prior to undertaking the pre-training assessment, participants were asked to fill out a questionnaire regarding their confidence in the use of $A A C$, the same questionnaire was completed at the end of the training interventions. Along with confidence, participants were asked their views with regard to switching Barrett's surveillance assessments from 4 quadrant biopsies to an AA-targeted technique.

\section{Validation of the assessment test}

Prior to use, the content of the assessment test was evaluated to ensure it differentiates between experts and novices in AAC-assisted lesion recognition. Two experts in the use of AA (PB, GLW) not involved in the selection of the images and videos for the test module, completed the test to benchmark expert performance. To evaluate performance of the test for novices in the AAC, 3 independent endoscopists ( 1 Gl-fellow, 2 consultant gastroenterologists) completed the same test module. Neither the experts nor the novices were involved in the subsequent training exercise. 


\section{$\underline{\text { Statistical analysis }}$}

To investigate the construct validity of the assessment test, we assumed sensitivity achieved by expert AA users was $90 \%$ and non-users $70 \%$, based on the validation exercise for the assessment test (Table 2a\&b). For a chi-squared test using a 5\% significance level, with $80 \%$ power and a baseline difference of $20 \%, 59$ independent observations would need to be recorded. However, because the data are not truly independent (same images and videos shown to different observers) we assumed that double the number of observations would satisfy the power calculation.

To examine the content validity of the training module a $10 \%$ improvement in sensitivity between pre- $(70 \%)$ and post-training $(80 \%)$ performance was deemed to be clinically relevant. For a chisquared test with $5 \%$ significance level and $80 \%$ power, and again assuming the data are not truly independent, at least 291 observations would be required. Again, because the data are not truly independent, we assumed 780 observations for each stage of assessment, from 13 observers, would more than satisfy the power calculation

Sensitivity, specificity, accuracy, positive predictive value (PPV) and negative predictive value (NPV,) were calculated for each observer $(n=13)$ at each timepoint, using histopathological diagnosis as the reference standard. All analysis was performed using these summary values. Confidence intervals were calculated to illustrate the uncertainty in the estimated values, and, the 2-sided, paired t-test was used to compare between timepoints. A p-value $<0.05$ was deemed to be significant.

Interobserver agreement for images and videos was assessed using the multi-rater Fleiss kappa $(\kappa)$ statistic. A $\kappa$ value $<0.2$ was regarded as poor agreement, 0.21-0.40 fair agreement, 0.41-0.60 moderate agreement, 0.61-0.80 substantial agreement, 0.81-1.00 almost perfect agreement.

Analyses were performed using the SPSS statistical package, version 22 for Macintosh (IBM corp). 


\section{Results}

\section{Validation of the assessment module}

Outcomes of the assessment module validation exercise are shown in Table 2a\&b. These results were used to power the number of participants required for the study. Overall there was a significant difference in performance of experts and novices in both images and video-based assessment. Agreement between experts was extremely high and between novices fair.

\section{RESULTS OF TRAINING}

\section{Intervention 1: Online training}

13 participants consented to the study. Assessment images and videos were completed prior to the online training module, with outcomes shown in Table 3a\&b. Following online training, the assessment tool was completed demonstrating poor baseline performance but a significant improvement in sensitivity and NPV following the online training module.

\section{Intervention 2: Interactive Seminar: dedicated lectures and live case demonstration}

Following completion of the interactive training day the assessment tool was repeated (Table 4a\&b) showing a statistically significant improvement in sensitivity and NPV for videos and a trend for improvement for images.

\section{Comparison of outcomes: Image vs Video assessments}

Assessment by images is no different from assessment by videos (Table 4), suggesting still-images serve as a reliable surrogate of videos.

Results overall showed improvement in performance after each intervention. The greatest improvement in performance occurred after online training. Additional clinically relevant improvements, in particular for NPV, were seen following the interactive training day. 


\section{Subgroup analysis of Experienced ( $\mathrm{n}>50$ procedures) Acetic Acid Users versus Non-experienced}

Table 6 a\&b shows a subgroup analysis comparing acetic acid users $(n=6)$ those who had performed over 50 acetic acid procedures prior to study enrolment compared to those who had done fewer, acetic acid naïve $(n=7)$.

\section{Confidence in technique}

Endoscopist confidence in the use of the AAC-technique increased throughout training with a mean pre-training confidence level of 2.5 (5-point scale) with a post-training confidence level of 3.9 $(p<0.001)$. Training increased the willingness of endoscopists to switch from a $2 \mathrm{~cm}$ quadrantic biopsy protocol to an AA-targeted technique with a mean willingness pre-training of 2.6 (5-point scale) rising to 3.8 post-training $(p<0.001)$. Confidence in in-vivo diagnosis for images also improved during training with mean number of diagnoses made with high confidence $41 \%$ pre training rising to $63 \%$ after the online training module $(p<0.001)$. The same was true for videos with mean number of diagnoses made with high confidence pre-training $47 \%$ rising to $67 \%$ following the online training module $(p<0.001)$. Following the interactive training day high-confidence responses rose from $63 \%$ to $72 \%$ for images $(p=0.045)$ and remained at $67 \%$ for videos.

\section{Discussion}

This study demonstrates the development of a novel training module for AAC-assisted in-vivo diagnosis of Barrett's neoplasia. We have demonstrated the feasibility of training in AAC by a wellvalidated training module. The advantage of the online training platform is that endoscopists can complete training at their own convenience. On average the online module takes 3 hours to complete. Additional clinical benefit was demonstrated from the interactive training day which we believe is integral to achieving competence in AAC-assisted lesion recognition in BE.

Participants included endoscopists from a variety of backgrounds all of whom demonstrated clinically relevant improvements in accuracy, sensitivity and NPV for the detection of Barrett's 
neoplasia with AAC. This demonstrates the validity, effectiveness and widespread applicability of this tool. The technique of AAC is very simple and can be performed by any endoscopist but our data shows that lesion recognition after AAC is not that easy and requires training. This is demonstrated by our baseline assessment data which showed poor performance (pre-training) from both very experienced and inexperienced Barrett's endoscopists, justifying the need and role of our training tool.

There were significant improvements in the interobserver agreement following training with substantial agreement achieved by the end of training. This is important as previous studies [29] have demonstrated low interobserver agreement of non-experts without training in AAC. Clearly, with training interobserver agreement improves.

This study demonstrates that the technique of in-vivo diagnosis for Barrett's neoplasia using AA can be taught using images and videos. However, it appears that endoscopists find it harder to diagnose neoplasia from videos as opposed to still-images. This can be explained as static images have been pre-selected to focus on neoplasia, whereas videos focus on the entire Barrett's segment, requiring more complex interpretation. Video performance improves following training. Sensitivity and NPV improved significantly following the interactive seminar but accuracy and specificity decreased. This can be explained by a higher number of false positives making AA safer-reducing the risk of missed neoplasia. At the end of the training exercise the sensitivity was $98 \%$ and $99 \%$ for images and videos respectively which is well above the $\geq 90 \%$ required by the ASGE PIVI criteria ${ }^{28}$. The same is true for NPV with mean scores of $97 \%$ and $98 \%$ for images and videos respectively again reaching the ASGE PIVI criteria ${ }^{28}$ of $\geq 98 \%$. We believe that it is high NPV which is most critical, as this suggests that the neoplasia miss-rate is minimal, highlighting the safety of the technique. The recent ASGE position statement [30] supports AAC targeted-biopsy in expert hands but our data shows that those with training can achieve the same thresholds as experts with our image and video-based assessments.

Training modules on lesion recognition and in-vivo diagnosis have traditionally relied on static images. In real-life, assessments are made on dynamic and moving images. Therefore, assessment and training of endoscopists in AAC-assisted lesion recognition, would in theory, be better performed using video-clips, that more closely reflect real-time practice. Our data, however, show no significant difference in performance when endoscopists are assessed using images or videos. 
There are some limitations to this study. We don't know whether success in this training module using images and videos, translates to success in real-life cases. We hope to answer this question following the completion of our randomised, crossover, tandem endoscopy study comparing Seattle protocol and AA-targeted biopsy in Barrett's surveillance (The ABBA Study)[31]. Our construct validity data showed that experts in this field had high sensitivity (95-100\%) and high NPV (95$100 \%)$. At the end of training, even non-expert, AAC naïve endoscopists were able to achieve sensitivity and specificity within expert range. We believe this important finding demonstrates the strength of our training pathway. We are unable to answer the question as to whether performance drops off with time as there were only 2 weeks between completion of the online training module and the interactive seminar. Another limitation is that the images and videos selected did not include low grade dysplasia, endoscopic recognition of low grade dysplasia is challenging but an important entity given the recent evidence for ablation of low grade dysplasia[32].

This study has a robust design with a well-validated library of images and videos where the performance of the library was validated prior to its use. This study proves the effectiveness of an online training module for $A A C$ and demonstrates the added clinical value of an interactive training day incorporating expert endoscopists and live cases.

\section{Conclusions}

Acetic acid chromoendoscopy is a readily available and cheap technology that has the potential to improve Barrett's surveillance and neoplasia yield. This study suggests that the technique can be taught effectively through a simple and easy to implement training module that could be rolled out on a larger scale. We have demonstrated that the tool has good construct and validity and is universally applicable for endoscopists of all backgrounds, but favours those with limited or no acetic acid experience. 


\section{Acknowledgements:}

The authors would like to acknowledge the following people for their involvement in the study: $\mathrm{Dr}$ Angel De Silva, Dr Tim Trebble, Dr Gareth Sadler, Denise Bools, Sara Green, Kirsty Harding, Tracey Jarvis, Susan Baker, Barbara Willett. As well as Paul Bassett for statistical support.

Bhat S, Coleman HG, Yousef F, Johnston BT, McManus DT, Gavin AT, Murray LJ. Risk of malignant progression in Barrett's Esophagus patients: Results from a large populationbased study. J Natl Cancer Inst 2011; 103: 1049-1057 Office for national statistics. Cancer survival in England: adults diagnosed in 2009 to 2013, followed up to 2014. 2014; 1-14 Available from: http://www.cancerresearchuk.org/healthprofessional/cancer-statistics/statistics-by-cancer-type/lung-cancer/survival\#heading-One de Jonge PJF, van Blankenstein M, Grady WM, Kuipers EJ. Barrett's oesophagus: epidemiology, cancer risk and implications for management. Gut 2014; 63: 191-202 Available from: http://www.ncbi.nlm.nih.gov/pubmed/24092861 Hvid-Jensen F, Pedersen L. Incidence of Adenocarcinoma among Patients with Barrett's Esophagus. Engl J 2011; 1375-1383 Available from:

http://www.nejm.org/doi/full/10.1056/NEJMoa1103042 Yousef F, Cardwell C, Cantwell MM, Galway K, Johnston BT, Murray L. The incidence of esophageal cancer and high-grade dysplasia in Barrett's esophagus: A systematic review and meta-analysis. Am J Epidemiol 2008; 168: 237-249 Sharma P, Falk GW, Weston AP, Reker D, Johnston M, Sampliner RE. Dysplasia and cancer in a large multicenter cohort of patients with Barrett's esophagus. Clin Gastroenterol Hepatol 2006; 4: 566-572 Available from: http://www.cghjournal.org/article/S1542-3565(06)002278/abstract Picardo SL, O'Brien MP, Feighery R, O’Toole D, Ravi N, O'Farrell NJ, O'Sullivan JN, Reynolds J V. A Barrett's esophagus registry of over 1000 patients from a specialist center highlights greater risk of progression than population-based registries and high risk of low grade dysplasia. Dis Esophagus 2015; 28: 121-126 Available from: http://www.embase.com/search/results?subaction=viewrecord\&from=export\&id=L529661 30 esophageal adenocarcinoma in Barrett's esophagus with low-grade dysplasia: A systematic 
review and meta-analysis. Gastrointest Endosc 2014; 79

Konda VJA, Ross AS, Ferguson MK, Hart JA, Lin S, Naylor K, Noffsinger A, Posner MC, Dye C,

Cislo B, Stearns L, Waxman I. Is the Risk of Concomitant Invasive Esophageal Cancer in HighGrade Dysplasia in Barrett's Esophagus Overestimated? Clin Gastroenterol Hepatol 2008; 6: 159-164

Heitmiller RF, Redmond M, Hamilton SR. Barrett's esophagus with high-grade dysplasia. An indication for prophylactic esophagectomy. AnnSurg 1996; 224: 66-71

Fitzgerald RC, di Pietro M, Ragunath K, Ang Y, Kang J-Y, Watson P, Trudgill N, Patel P, Kaye P V, Sanders S, O’Donovan M, Bird-Lieberman E, Bhandari P, Jankowski J a, Attwood S, Parsons SL, Loft D, Lagergren J, Moayyedi P, Lyratzopoulos G, de Caestecker J. British Society of Gastroenterology guidelines on the diagnosis and management of Barrett's oesophagus. Gut 2014; 63: 7-42 Available from:

http://www.ncbi.nlm.nih.gov/pubmed/24165758

Pech O, Gossner L, Manner H, May A, Rabenstein T, Behrens A, Berres M, Huijsmans J, Vieth M, Stolte M, Ell C. Prospective evaluation of the macroscopic types and location of early Barrett's neoplasia in 380 lesions. Endoscopy 2007; 39: 588-593

Kariv R, Plesec TP, Goldblum JR, Bronner M, Oldenburgh M, Rice TW, Falk GW. The Seattle Protocol Does Not More Reliably Predict the Detection of Cancer at the Time of Esophagectomy Than a Less Intensive Surveillance Protocol. Clin Gastroenterol Hepatol 2009; 7: 653-658

Peters FP, Curvers WL, Rosmolen WD, De Vries CE, Ten Kate FJW, Krishnadath KK, Fockens P, Bergman JJGHM. Surveillance history of endoscopically treated patients with early Barrett's neoplasia: nonadherence to the Seattle biopsy protocol leads to sampling error. Dis Esophagus 2008; 21: 475-479 Available from: http://doi.wiley.com/10.1111/j.14422050.2008.00813.x

Abrams JA, Kapel RC, Lindberg GM, Saboorian MH, Genta RM, Neugut Al, Lightdale CJ. Adherence to Biopsy Guidelines for Barrett's Esophagus Surveillance in the Community Setting in the United States. Clin Gastroenterol Hepatol 2009; 7: 736-742

Ragunath K, Krasner N, Raman VS, Haqqani MT, Cheung WY. A randomized, prospective cross-over trial comparing methylene blue-directed biopsy and conventional random biopsy for detecting intestinal metaplasia and dysplasia in Barrett's esophagus. Endoscopy 2003; 35: 998-1003 Ngamruengphong S, Sharma VK, Das A. Diagnostic yield of methylene blue 
chromoendoscopy for detecting specialized intestinal metaplasia and dysplasia in Barrett's esophagus: a meta-analysis. Gastrointest Endosc 2009; 69: 1021-1028

Kara MA, Peters FP, Ten Kate FJW, Van Deventer SJ, Fockens P, Bergman JJGHM. Endoscopic video autofluorescence imaging may improve the detection of early neoplasia in patients with Barrett's esophagus. Gastrointest Endosc 2005; 61: 679-685 Curvers WL, Herrero LA, Wallace MB, Wong Kee Song LM, Ragunath K, Wolfsen HC, Prasad GA, Wang KK, Subramanian V, Weusten BLAM, Ten Kate FJ, Bergman JJGHM. Endoscopic trimodal imaging is more effective than standard endoscopy in identifying early-stage neoplasia in Barrett's esophagus. Gastroenterology 2010; 139 Curvers WL, Van Vilsteren FG, Baak LC, Böhmer C, Mallant-Hent RC, Naber AH, Van Oijen A, Ponsioen CY, Scholten P, Schenk E, Schoon E, Seldenrijk CA, Meijer GA, Kate FJ Ten, Bergman JJ. Endoscopic trimodal imaging versus standard video endoscopy for detection of early Barrett's neoplasia: A multicenter, randomized, crossover study in general practice. Gastrointest Endosc 2011; 73: 195-203 Lambert R, Rey JF, Sankaranarayanan R. Magnification and chromoscopy with the acetic acid test. Endoscopy 2003; 35: 437-445 Available from: http://www.ncbi.nlm.nih.gov/pubmed/12701018 Longcroft-Wheaton G, Brown J, Basford P, Cowlishaw D, Higgins B, Bhandari P. Duration of acetowhitening as a novel objective tool for diagnosing high risk neoplasia in Barrett's esophagus: A prospective cohort trial. Endoscopy 2013; 45: 426-432 Longcroft-Wheaton G, Duku M, Mead R, Poller D, Bhandari P. Acetic acid spray is an effective tool for the endoscopic detection of neoplasia in patients with barrett's esophagus. Clin Gastroenterol Hepatol 2010; 8: 843-847 Available from: http://dx.doi.org/10.1016/j.cgh.2010.06.016 Pohl J, Pech O, May A, Manner H, Fissler-Eckhoff A, Ell C. Incidence of macroscopically occult neoplasias in Barrett's esophagus: are random biopsies dispensable in the era of advanced endoscopic imaging? Am J Gastroenterol 2010; 105: 2350-2356 Available from: http://dx.doi.org/10.1038/ajg.2010.280 Bhandari P, Kandaswamy P, Cowlishaw D, Longcroft-Wheaton G. Acetic acid-enhanced chromoendoscopy is more cost-effective than protocol-guided biopsies in a high-risk Barrett's population. Dis Esophagus 2012; 25: 386-392 chromoendoscopy in Barrett's esophagus surveillance is superior to the standardized 
random biopsy protocol: Results from a large cohort study (with video). Gastrointest Endosc 2014; 80: 417-424 Available from: http://dx.doi.org/10.1016/j.gie.2014.01.041 Sharma P, Savides TJ, Canto MI, Corley DA, Falk GW, Goldblum JR, Wang KK, Wallace MB, Wolfsen HC. The American Society for Gastrointestinal Endoscopy PIVI (Preservation and Incorporation of Valuable Endoscopic Innovations) on imaging in Barrett's Esophagus. Gastrointest Endosc 2012; 76: 252-254 Available from: http://linkinghub.elsevier.com/retrieve/pii/S001651071202247X Kandiah K, Chedgy FJQ, Longcroft-Wheaton G, Pech O, De Caestecker J, Green S, Gordon C, Li A, Barr H BP. Development and Validation of a Calssification system to identify Barrett's Neoplasia using acetic acid chromoendoscopy: The PREDICT Classification. 2016; 7: 2016 Curvers W, Baak L, Kiesslich R, Van Oijen A, Rabenstein T, Ragunath K, Rey JF, Scholten P, Seitz U, Ten Kate F, Fockens P, Bergman J. Chromoendoscopy and Narrow-Band Imaging Compared With High-Resolution Magnification Endoscopy in Barrett's Esophagus. Gastroenterology 2008; 134: 670-679 Thosani N, Abu Dayyeh BK, Sharma P, Aslanian HR, Enestvedt BK, Komanduri S, Manfredi M, Navaneethan U, Maple JT, Pannala R, Parsi MA, Smith ZL, Sullivan SA, Banerjee S. ASGE Technology Committee systematic review and meta-analysis assessing the ASGE Preservation and Incorporation of Valuable Endoscopic Innovations thresholds for adopting real-time imaging-assisted endoscopic targeted biopsy during endoscopic surveillance. Gastrointest Endosc 2016; 83: 684-698.e7 Available from: http://linkinghub.elsevier.com/retrieve/pii/S0016510716000304 Date RR, Bhandari P, Hospitals P, Trust NHS, Brighton P. The Role of Vinegar in Identifying Abnormal Cells in Barrett' s Oesophagus . ( ABBA ). 2015; 3-5

Phoa KN, van Vilsteren FGI, Weusten BL a. M, Bisschops R, Schoon EJ, Ragunath K, Fullarton G, Di Pietro M, Ravi N, Visser M, Offerhaus GJ, Seldenrijk C a., Meijer SL, ten Kate FJW, Tijssen JGP, Bergman JJGHM. Radiofrequency Ablation vs Endoscopic Surveillance for Patients With Barrett Esophagus and Low-Grade Dysplasia. Jama 2014; 311: 1209 Available from:

http://jama.jamanetwork.com.proxy.kib.ki.se/article.aspx?articleid=1849991 \nhttp://jama.j amanetwork.com/article.aspx?doi=10.1001/jama.2014.2511 


\begin{tabular}{|c|c|c|c|c|}
\hline \multirow[t]{2}{*}{ Job title } & Years & No of OGD's & No of Barrett's & Number of AAC \\
\hline & \multicolumn{4}{|c|}{ Experience } \\
\hline 1. Cons GI Physician & 33 & 10,000 & 1500 & 200 \\
\hline 2. Cons GI Physician & 13 & 6,500 & 1,000 & 225 \\
\hline 3. Cons GI Physician & 15 & 10,000 & 1,250 & 300 \\
\hline 4. Cons GI Physician & 15 & 8,000 & 700 & 100 \\
\hline 5. Cons GI Physician & 17 & 5,000 & 880 & 60 \\
\hline 6. Cons GI Surgeon & 45 & 17,000 & 4,000 & 0 \\
\hline 7. Cons GI Surgeon & 18 & 7,000 & 2,000 & 0 \\
\hline 8. Nurse Endoscopist & 12 & 8000 & 3,000 & 0 \\
\hline 9. Nurse Endoscopist & 7 & 8,400 & 1,680 & 288 \\
\hline 10. Nurse Endoscopist & 4 & 2496 & 381 & 1 \\
\hline 11. Nurse Endoscopist & 2 & 695 & 76 & 4 \\
\hline 12. Nurse Endoscopist & 9 & 9,000 & 1,000 & 1 \\
\hline 13. Nurse Endoscopist & 12 & 15,000 & 1,500 & 1 \\
\hline
\end{tabular}

Table 1: Experience and Background of endoscopists enrolled in the study

\begin{tabular}{|c|c|c|c|c|c|c|}
\hline Group & Accuracy & Sensitivity & Specificity & PPV & NPV & Карра \\
\hline Experts $n=2$ & $\begin{array}{l}96 \% \\
(0.88-0.96)\end{array}$ & $\begin{array}{l}100 \% \\
(0.92-1.0)\end{array}$ & $\begin{array}{l}93 \% \\
(0.85-0.93)\end{array}$ & $\begin{array}{l}93 \% \\
(0.85-0.93)\end{array}$ & $\begin{array}{l}100 \% \\
(0.91-1.0)\end{array}$ & 0.80 \\
\hline Novices $n=3$ & $\begin{array}{l}73 \% \\
(0.63-0.80)\end{array}$ & $\begin{array}{l}72 \% \\
(0.62-0.80)\end{array}$ & $\begin{array}{l}73 \% \\
(0.64-0.81)\end{array}$ & $\begin{array}{l}71 \% \\
(0.61-0.79)\end{array}$ & $\begin{array}{l}74 \% \\
(0.65-0.82)\end{array}$ & 0.30 \\
\hline$P$-Value & $=0.009$ & $=0.096$ & $=0.313$ & $=0.111$ & $=0.019$ & \\
\hline
\end{tabular}

Table 2a: Validation of the test module (95\% Confidence Interval) showing significant difference in performance between experts and novices when assessed with still-images. 


\begin{tabular}{|c|c|c|c|c|c|c|}
\hline Group & Accuracy & Sensitivity & Specificity & PPV & NPV & Kappa \\
\hline Experts $n=2$ & $\begin{array}{l}97.50 \% \\
(0.84-0.98)\end{array}$ & $\begin{array}{l}95 \% \\
(0.81-0.95)\end{array}$ & $\begin{array}{l}100 \% \\
(0.86-1.0)\end{array}$ & $\begin{array}{l}100 \% \\
(0.85-1.0)\end{array}$ & $\begin{array}{l}95 \% \\
(0.82-0.95)\end{array}$ & 0.9 \\
\hline Novices $n=3$ & $\begin{array}{l}77 \% \\
(0.63-0.87)\end{array}$ & $\begin{array}{l}77 \% \\
(0.63-0.87)\end{array}$ & $\begin{array}{l}77 \% \\
(0.63-0.87)\end{array}$ & $\begin{array}{l}77 \% \\
(0.63-0.87)\end{array}$ & $\begin{array}{l}77 \% \\
(0.63-0.87)\end{array}$ & 0.40 \\
\hline$P$-value & $=0.021$ & $=0.408$ & $=0.133$ & $=0.018$ & $=0.382$ & \\
\hline
\end{tabular}

Table 2b: Validation of the test module (95\% Confidence Interval) showing significant difference in performance between experts and novices when assessed with dynamic videos.

\begin{tabular}{|c|c|c|c|c|c|c|}
\hline & Accuracy & Sensitivity & Specificity & PPV & NPV & Kappa \\
\hline Baseline & $\begin{array}{c}79 \% \\
0.75-0.83\end{array}$ & $\begin{array}{c}83 \% \\
0.79-0.86\end{array}$ & $\begin{array}{c}76 \% \\
0.73-0.79\end{array}$ & $\begin{array}{c}76 \% \\
0.72-0.79\end{array}$ & $\begin{array}{c}83 \% \\
0.79-0.86\end{array}$ & 0.48 \\
\hline $\begin{array}{l}\text { Post-Online } \\
\text { Training }\end{array}$ & $\begin{array}{c}86 \% \\
0.83-0.88\end{array}$ & $\begin{array}{c}95 \% \\
0.92-0.97\end{array}$ & $\begin{array}{c}79 \% \\
0.76-0.81\end{array}$ & $\begin{array}{c}80 \% \\
0.78-0.82\end{array}$ & $\begin{array}{c}94 \% \\
0.91-0.98\end{array}$ & 0.67 \\
\hline$P$-value & $<0.01$ & $<0.01$ & $=0.522$ & $=0.459$ & $<0.01$ & \\
\hline
\end{tabular}

Table 3a: Baseline assessment vs post online training assessment (95\% Confidence Interval) Images, significant improvement in accuracy, sensitivity and negative predictive value.

\begin{tabular}{|l|c|c|c|c|c|c|}
\hline & Accuracy & Sensitivity & Specificity & PPV & NPV & Kappa \\
\hline Baseline & $78 \%$ & $73 \%$ & $83 \%$ & $81 \%$ & $76 \%$ & 0.41 \\
& $0.72-0.83$ & $0.67-0.78$ & $0.77-0.88$ & $0.75-0.87$ & $0.70-0.80$ & \\
\hline Post-Online & $82 \%$ & $91 \%$ & $74 \%$ & $78 \%$ & $89 \%$ & 0.51 \\
Training & $0.77-0.86$ & $0.86-0.95$ & $0.69-0.78$ & $0.73-0.81$ & $0.83-0.94$ & \\
\hline P-value & $=0.281$ & $=0.011$ & $=0.194$ & $=0.505$ & $=0.041$ & \\
\hline
\end{tabular}

Table 3b: Baseline assessment vs post online training assessment (95\% Confidence Interval) Videos, significant improvement in sensitivity and negative predictive value.

\begin{tabular}{|l|c|c|c|c|c|c|}
\hline & Accuracy & Sensitivity & Specificity & PPV & NPV & Kappa \\
\hline Post-Online & $86 \%$ & $95 \%$ & $79 \%$ & $80 \%$ & $94 \%$ & 0.67 \\
\hline Training & $0.83-0.88$ & $0.92-0.97$ & $0.76-0.81$ & $0.78-0.82$ & $0.91-0.98$ & \\
\hline Interactive & $82 \%$ & $98 \%$ & $68 \%$ & $74 \%$ & $97 \%$ & 0.75 \\
Seminar & $0.80-0.84$ & $0.95-0.99$ & $0.66-0.69$ & $0.72-0.75$ & $0.94-0.99$ & \\
\hline P-value & $=0.028$ & $=0.084$ & $=0.007$ & $=0.002$ & $=0.131$ & \\
\hline
\end{tabular}

Table 4a: Post-online training assessment vs Interactive training day (95\% Confidence Interval) Images. Improvements in sensitivity and NPV. 


\begin{tabular}{|l|c|c|c|c|c|c|}
\hline & Accuracy & Sensitivity & Specificity & PPV & NPV & Kappa \\
\hline Post-Online & $82 \%$ & $91 \%$ & $74 \%$ & $78 \%$ & $89 \%$ & 0.51 \\
\hline Training & $0.77-0.86$ & $0.86-0.95$ & $0.69-0.78$ & $0.73-0.81$ & $0.83-0.94$ & \\
\hline Interactive & $79 \%$ & $99 \%$ & $60 \%$ & $71 \%$ & $98 \%$ & 0.63 \\
Seminar & $0.75-0.81$ & $0.95-1.0$ & $0.56-0.61$ & $0.68-0.72$ & $0.91-1.0$ & \\
\hline P-value & $=0.322$ & $=0.003$ & $=0.005$ & $=0.035$ & $=0.004$ & \\
\hline
\end{tabular}

Table 4b: Post online training assessment vs Interactive training day (95\% Confidence Interval) Videos demonstrating statistically significant improvement in sensitivity and negative predictive value.

\begin{tabular}{|c|c|c|c|c|c|}
\hline & Accuracy & Sensitivity & Specificity & PPV & NPV \\
\hline $\begin{array}{l}\text { Pre-training } \\
\text { Images }\end{array}$ & $\begin{array}{c}79 \% \\
0.75-0.83\end{array}$ & $\begin{array}{c}83 \% \\
0.79-0.86\end{array}$ & $\begin{array}{c}76 \% \\
0.73-0.79\end{array}$ & $\begin{array}{c}76 \% \\
0.72-0.79\end{array}$ & $\begin{array}{c}83 \% \\
0.79-0.86\end{array}$ \\
\hline $\begin{array}{l}\text { Pre-training } \\
\text { Videos }\end{array}$ & $\begin{array}{c}78 \% \\
0.72-0.83\end{array}$ & $\begin{array}{c}73 \% \\
0.67-0.78\end{array}$ & $\begin{array}{c}83 \% \\
0.77-0.88\end{array}$ & $\begin{array}{c}81 \% \\
0.75-0.87\end{array}$ & $\begin{array}{c}76 \% * \\
0.70-0.80\end{array}$ \\
\hline $\begin{array}{l}\text { Post-Online } \\
\text { Training } \\
\text { Images }\end{array}$ & $\begin{array}{r}86 \% \\
0.83-0.88\end{array}$ & $\begin{array}{r}95 \% \\
0.92-0.97\end{array}$ & $\begin{array}{r}79 \% \\
0.76-0.81\end{array}$ & $\begin{array}{r}80 \% \\
0.78-0.82\end{array}$ & $\begin{array}{r}94 \% \\
0.91-0.98\end{array}$ \\
\hline $\begin{array}{l}\text { Post-Online } \\
\text { Training } \\
\text { Videos }\end{array}$ & $\begin{array}{c}82 \% \\
0.77-0.86\end{array}$ & $\begin{array}{c}91 \% \\
0.86-0.95\end{array}$ & $\begin{array}{c}74 \% \\
0.69-0.78\end{array}$ & $\begin{array}{c}78 \% \\
0.73-0.81\end{array}$ & $\begin{array}{c}89 \% \\
0.83-0.94\end{array}$ \\
\hline $\begin{array}{l}\text { Post-Seminar } \\
\text { Images }\end{array}$ & $\begin{array}{c}82 \% \\
0.80-0.84\end{array}$ & $\begin{array}{c}98 \% \\
0.95-0.99\end{array}$ & $\begin{array}{c}68 \% \\
0.66-0.69\end{array}$ & $\begin{array}{c}74 \% \\
0.72-0.75\end{array}$ & $\begin{array}{c}97 \% \\
0.94-0.99\end{array}$ \\
\hline $\begin{array}{l}\text { Post-Seminar } \\
\text { Videos }\end{array}$ & $\begin{array}{c}79 \% * \\
0.75-0.81\end{array}$ & $\begin{array}{c}99 \% \\
0.95-1.0\end{array}$ & $\begin{array}{c}60 \% * \\
0.56-0.61\end{array}$ & $\begin{array}{c}71 \% \\
0.68-0.72\end{array}$ & $\begin{array}{c}98 \% \\
0.91-1.0\end{array}$ \\
\hline
\end{tabular}

Table 5: Comparison of images and videos for each stage of training. $\left({ }^{*} p<0.05\right)$

\begin{tabular}{|l|l|l|l|l|l|l|l|l|l|l|}
\hline & \multicolumn{3}{c}{ Accuracy } & \multicolumn{2}{c|}{ Sensitivity } & \multicolumn{3}{c|}{ Specificity } & \multicolumn{3}{c|}{ PPV } & \multicolumn{2}{c|}{ NPV } \\
\hline & Naïve & User & Naïve & User & Naïve & User & Naïve & User & Naïve & User \\
\hline Pre-Training & $78 \%$ & $81 \%$ & $71 \%$ & $95 \%$ & $83 \%$ & $68 \%$ & $81 \%$ & $74 \%$ & $77 \%$ & $94 \%$ \\
\hline Post-Online & $85 \% *$ & $88 \% *$ & $92 \% *$ & $97 \%$ & $78 \%$ & $79 \% *$ & $80 \%$ & $81 \% *$ & $93 \% *$ & $97 \%$ \\
\hline Interactive & $83 \%$ & $82 \%$ & $97 \%$ & $99 \%$ & $70 \%$ & $66 \%$ & $75 \%$ & $72 \%$ & $97 \%$ & $99 \%$ \\
\hline Seminar & & & & & & & & & & \\
\hline
\end{tabular}

Table 6a Subgroup analysis of performance naïve vs users - Images $\left({ }^{*} p<0.05\right)$

\begin{tabular}{|l|l|l|l|l|l|l|l|l|l|l|l|}
\hline & \multicolumn{3}{c}{ Accuracy } & \multicolumn{3}{c|}{ Sensitivity } & \multicolumn{3}{c|}{ Specificity } & \multicolumn{3}{c|}{ PPV } & \multicolumn{3}{c|}{ NPV } \\
\hline & Naïve & User & Naïve & User & Naïve & User & Naïve & User & Naïve & User \\
\hline Pre-Training & $71 \%$ & $83 \%$ & $59 \%$ & $84 \%$ & $84 \%$ & $81 \%$ & $83 \%$ & $82 \%$ & $67 \%$ & $87 \%$ \\
\hline Post-Online & $82 \%$ & $83 \%$ & $90 \% *$ & $92 \%$ & $74 \%$ & $76 \%$ & $80 \%$ & $80 \%$ & $89 \% *$ & $89 \%$ \\
\hline Interactive & $81 \%$ & $78 \%$ & $99 \% *$ & $98 \% *$ & $63 \%$ & $57 \%$ & $73 \%$ & $71 \%$ & $98 \%$ & $98 \% *$ \\
\hline Seminar & & & & & & & & & & \\
\hline
\end{tabular}

Table $6 b$ Subgroup analysis of performance naïve vs users - Videos $\left({ }^{*} p<0.05\right)$ 


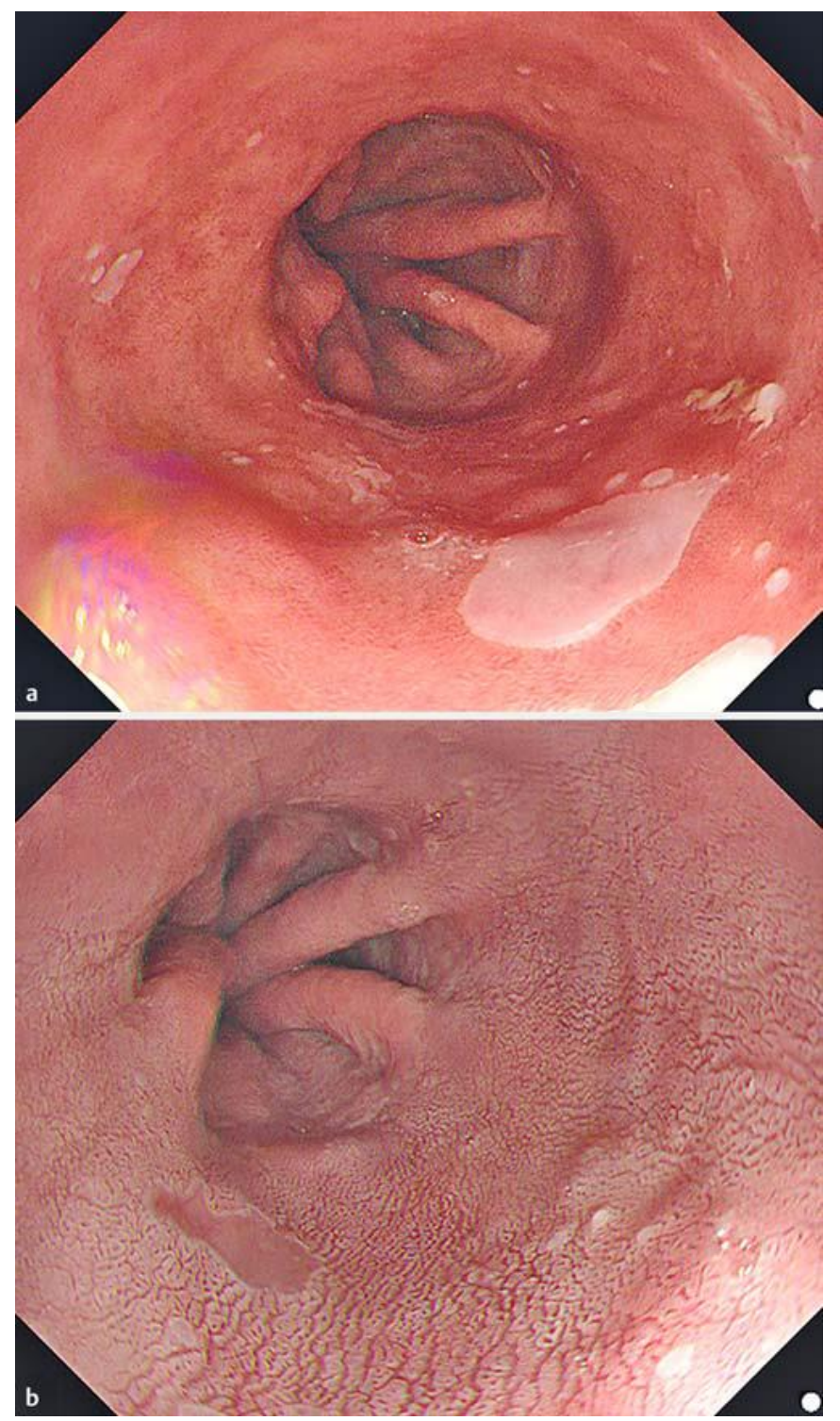

Figure 1a: Non-dysplastic Barrett's Mucosa

Figure $1 \mathrm{~b}$ : The same patient following AAC 


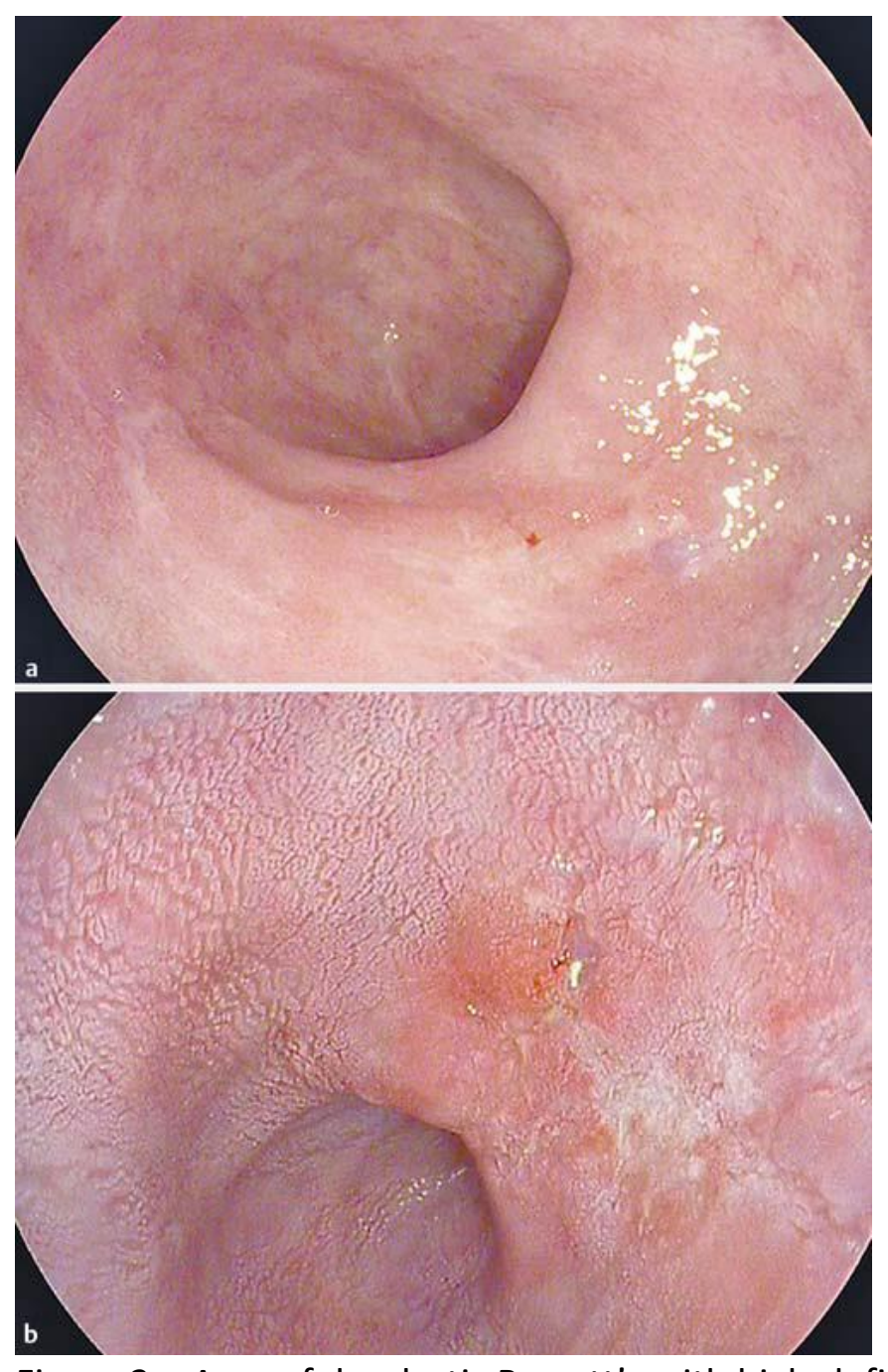

Figure 2a: Area of dysplastic Barrett's with high-definition white light

Figure 2b: AAC- assisted lesion recognition - area of dysplasia highlighted by early loss of acetowhitening 


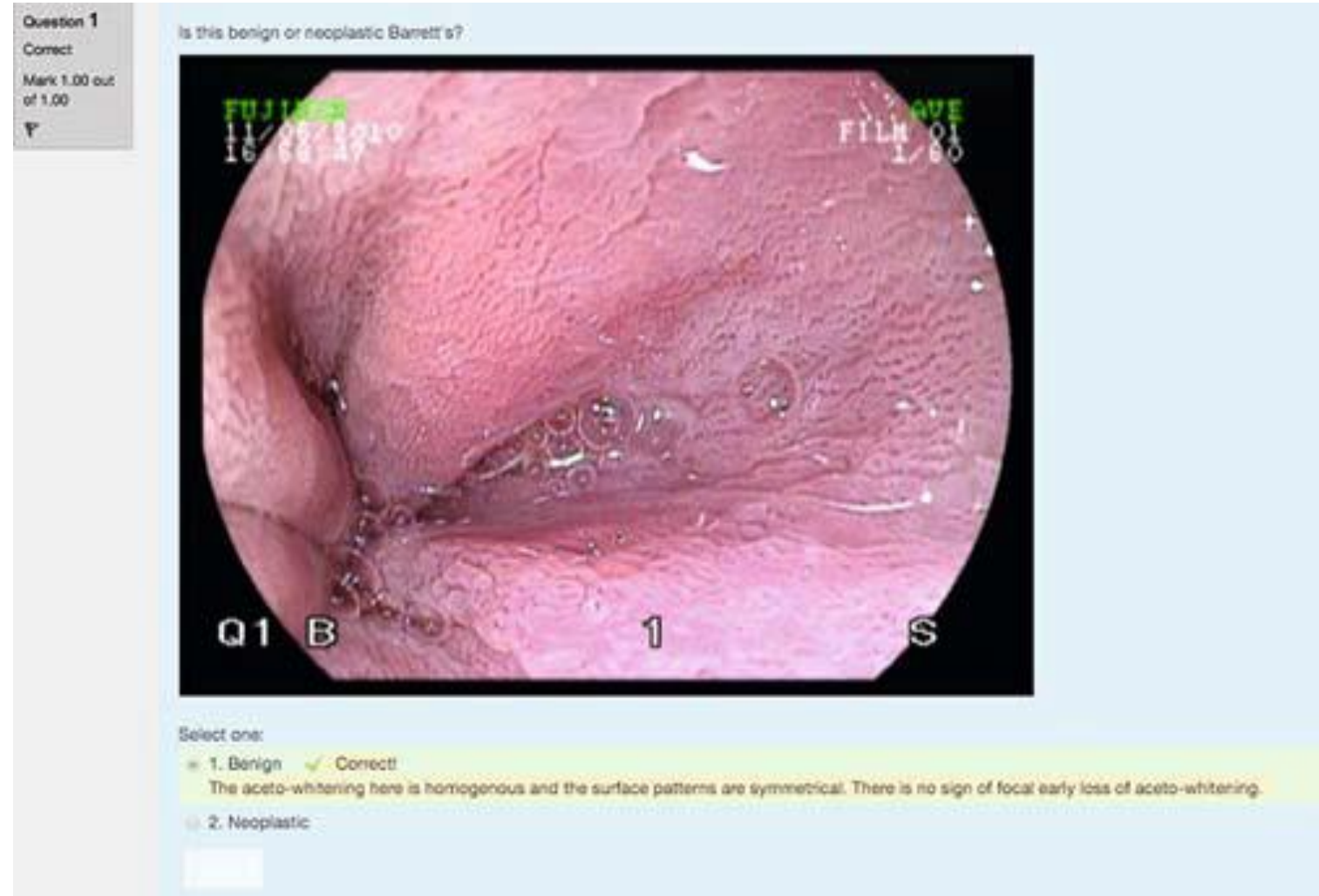

Figure 3: Example screenshot of online training module

Pre-training assessment

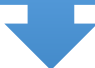

INTERVENTION 1: Online Training Module

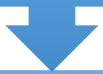

Post-online training assessment

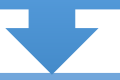

INTERVENTION 2: Live interactive workshop

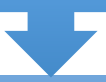

Post-workshop assessment

\section{Figure 4: Flow diagram of training and assessment}

